\title{
Monitoring of the collapse of the shores of reservoirs and the technology of their surface and deep fixing
}

\author{
Tatiana Zolina ${ }^{1, *}$, Sergei Strelkov ${ }^{1}$, Natalia Kupchikova ${ }^{1}$, and Kirill Kondrashin ${ }^{1}$ \\ ${ }^{1}$ Astrakhan State University of Architecture and Civil Engineering, 414056, Tatishcheva Street, 18, \\ Astrakhan, Russian Federation
}

\begin{abstract}
Due to the unique water regime of the Astrakhan region, characterized by an uneven distribution of runoff that is directly dependent on the discharge from the Volgograd hydroelectric power station, coastal zones of water bodies are subject to intense negative effects. It is established that, despite the existing variety of ways to protect coasts from erosion, the search for new technical solutions at the moment continues to be an urgent task in hydraulic construction. The purpose of this work was to evaluate the application of a new methodology for studying the destruction of coastal zones and the method of shore protection. The article discusses the features of work on shore protection of territories subject to slope processes. The role of studies of the leading processes of destruction of coastal zones in the course of engineering and geological surveys, to predict and prevent risk, as well as to ensure the information content of further work on the construction of reliable shore protection, is emphasized. The result of the study was a new method for identifying the destroyed coastal zones, technologies for surface and deep fixing of the Bank slopes, and a method for preventing the collapse of steep river banks. In this paper, a positive assessment of the investigated method of Bank protection was given. Research has shown that prevention of emergency situations, especially in urbanized areas subject to intense anthropogenic impact, is possible only with the construction of engineering protection structures that have a positive effect in both protective and environmental aspects.
\end{abstract}

\section{Introduction}

In the coastal zone, many types of human activity and interests are concentrated, which have increased significantly in the past few decades [1].

The coastal zone not only limits the riverbed, indicating its borders, but also performs many functions. One of which is protection, the rocks of the shore filter the groundwater entering the body of water [2].

Every year, despite the long-term process of destruction of the coastal zone, more and more rivers, rivers, fishing passages and shipping channels suffer from shallowing, and this

*Corresponding author: zolinatv@yandex.ru 
trend is applicable to almost all water bodies due to natural-historical and anthropogenic factors.

The coastline of water bodies is destroyed by prolonged exposure to direct current of water, as well as the critical effects of floods, showers and man-made activities.

c.

In addition, the collapse of the coast contribute daily, weekly and seasonal variations in water level caused mainly uneven operation of hydroelectric:

- Lowering the level during the discharge of the reservoir causes erosion of the accumulative part of the coastal shallow. Raising the level activates the processes of bank destruction.

- Also, an unprotected shore of an internal radius at the turning point of the river is most often subject to destruction, since the water flow in this section is accelerated.

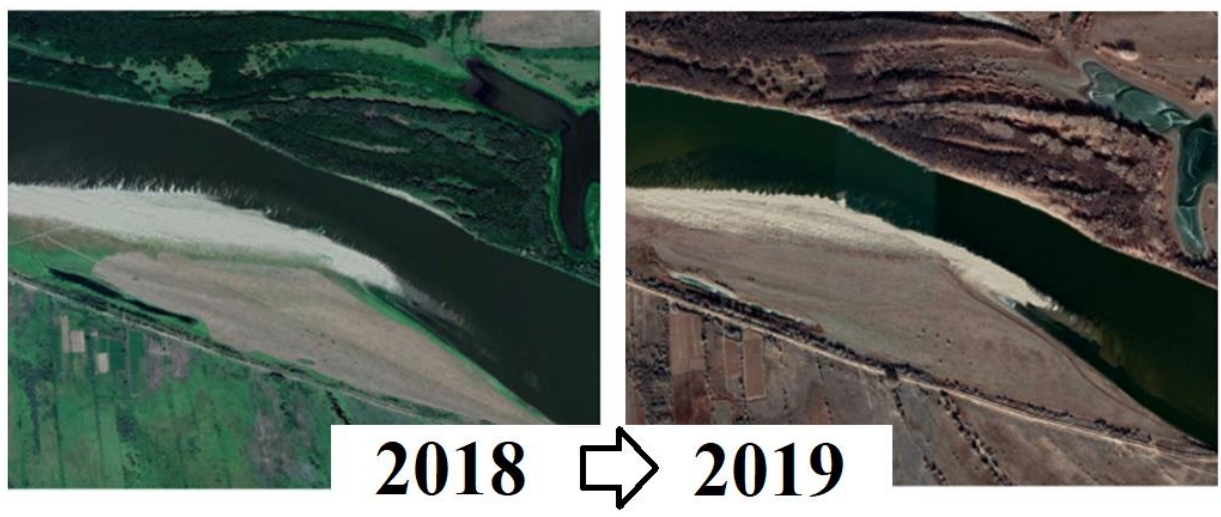

Fig. 1. Accumulation of alluvium in the destruction of the coastal zone. Source. https://www.google.com/intl/en/earth/

Assessing vulnerability to hazards is a key step towards greater effectiveness, reducing disaster risk and building resilience [3].

The periodic destruction of the coastline of water bodies with the subsequent deposition and accumulation of alluvium at the bottom of these reservoirs is a prerequisite for further very expensive dredging. Any dredging work, in turn, carried out to eliminate the consequences of the destruction of coastal zones, should be accompanied by environmental studies (monitoring). In the framework of environmental audits, the physicochemical negative impact of the work on all environments is investigated - air, water, bottom sediments, soil, vegetation, etc.

The study of the qualitative and quantitative chemical composition of the media is considered very important. Changes in the content of petroleum products, heavy metals, salt composition and suspended solids can critically affect the environment.

An alternative to expensive dredging can be preventive measures, that is, the study of the condition of coastal zones and shore protection work, where necessary.

\section{Methods}

Engineering and hydrological work to study the deformation of river channels and the banks of water bodies are carried out in conjunction with topographic, geodetic and geological work. Tracking of potentially dangerous zones is possible with the help of satellite images of different times and with the control of aerial photo shooting from UAVs (unmanned aerial vehicles: quadrocopters, drones), as well as modern geodetic equipment.

The algorithm for such work is as follows: 
The potentially dangerous zone (found from space images) is measured and limited (in the process of aerial photo shooting), and then specialists carry out measurements and calculations along the coastal zone (shore structure, slope angle, height of water rise, degree and possibility of destruction, etc.). d.).

In particular, it is necessary to investigate the mechanical composition of the shore, the water flow rate and other conditions determined during monitoring. The initial information for calculating the rate of shore erosion is the data of observations (surveys) of the amount of coastal retreat over a long period. To do this, you can use various mathematical and statistical methods of calculation [4].

The obtained measurements and calculations are subsequently used to form fortifications of the studied hazardous area. One of the tasks of engineering and geological surveys is to obtain materials for forecast estimates of changes in the position of the shore due to erosion, as well as to justify the selection and calculation of protective measures.

In 2019, as part of the research work by the departments of GKU and EUN of ASUACE, the project "Monitoring of the collapse of coastal zones and the technology of their surface and deep fixing" is being implemented. The project was presented as part of the XIII International Scientific and Practical Conference "Prospects for the Development of the Building Complex: Education, Science, Business".

Bank protection is currently divided into several types, by price and technology.

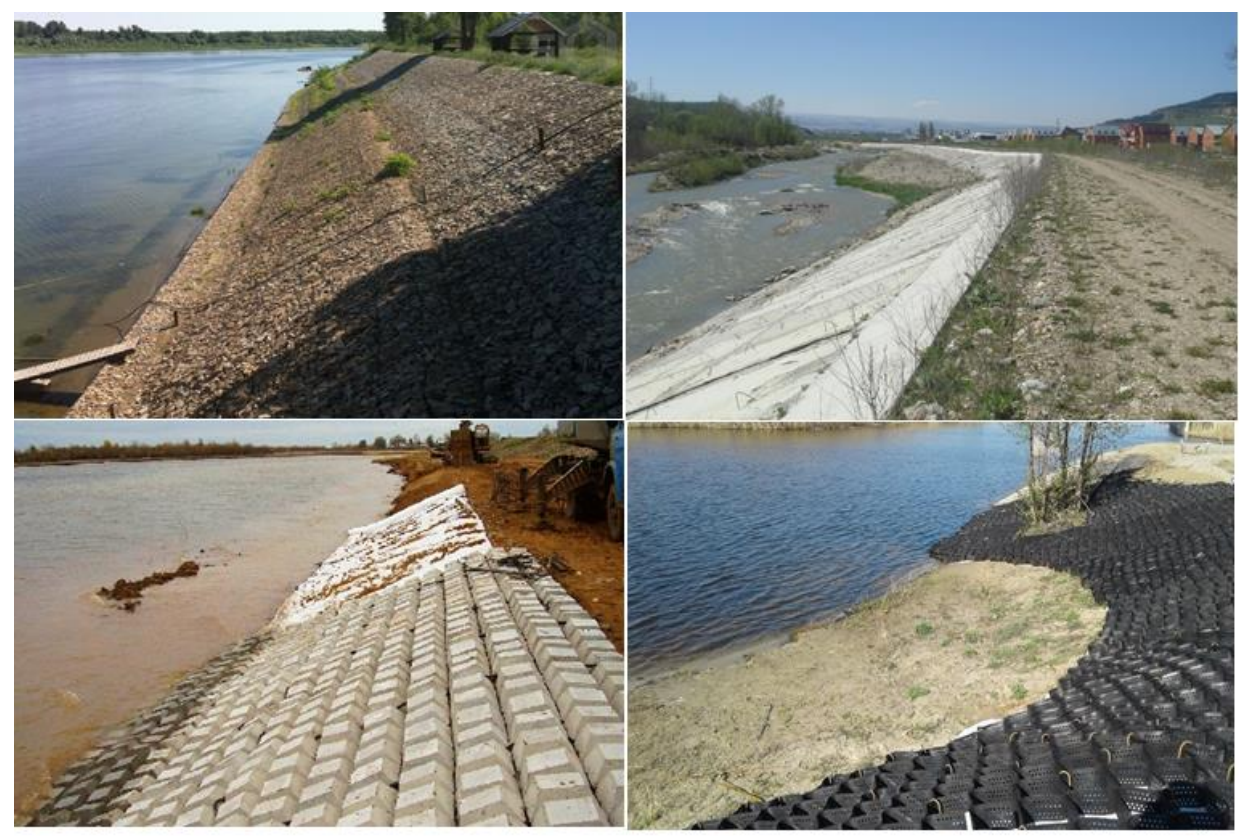

Fig. 2. Some types of shore protection structures.

Weight, coastal surface area and two-dimensional flexibility of a particular mattress (shore protection element), provides resistance against hydrodynamic wave loads [5].

There are no clear conclusions that one technology is better than another is there are both positive and negative sides. There are no bad materials, there is no their correct application.

Nowadays, a good example is the use of a combination of metal with reinforced concrete. In an industrial building, this is a combination of reinforced concrete columns and steel trusses.

When choosing construction technology designs need to answer a few questions: 
- What is available at the construction site: what resources, building materials?

- What should be the construction period?

- What are the requirements for the building: fire and technological?

- What is the way to deliver materials to the construction site?

- To provide for the possibility of expansion and modernization of production. [6]

\section{Results and discussions}

In the course of the work, technologies and algorithms for monitoring work were developed with the subsequent strengthening of potentially dangerous coastal zones.

Data processing and analysis was carried out on the basis of GIS software (ERDAS Imagine, Map Info) and included the following operations: spatial combination of different images, topographic, geological and landscape data; relative radiometric calibration of pictures.

\section{GTS NX}

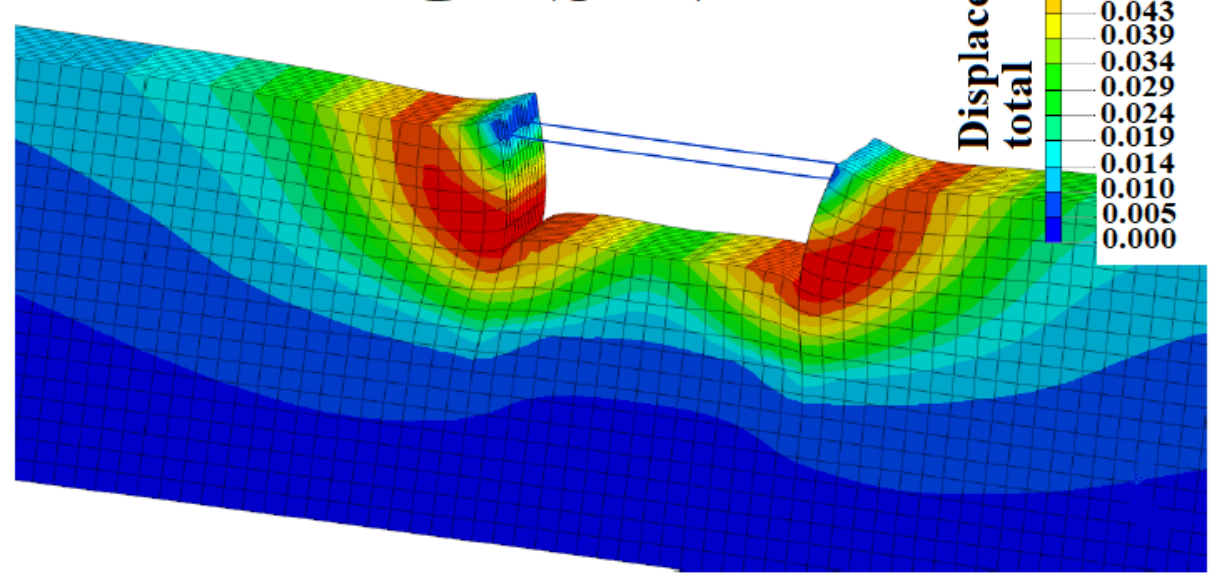

Fig.3. Processing technology design results using midas gts nx software.

Developed and patented technologies for surface and deep fixing of slopes of coastal zones, taking into account the regional conditions of the Astrakhan region by injection of low-viscosity solutions with additives, geosynthetic materials and micro pile dowels. 


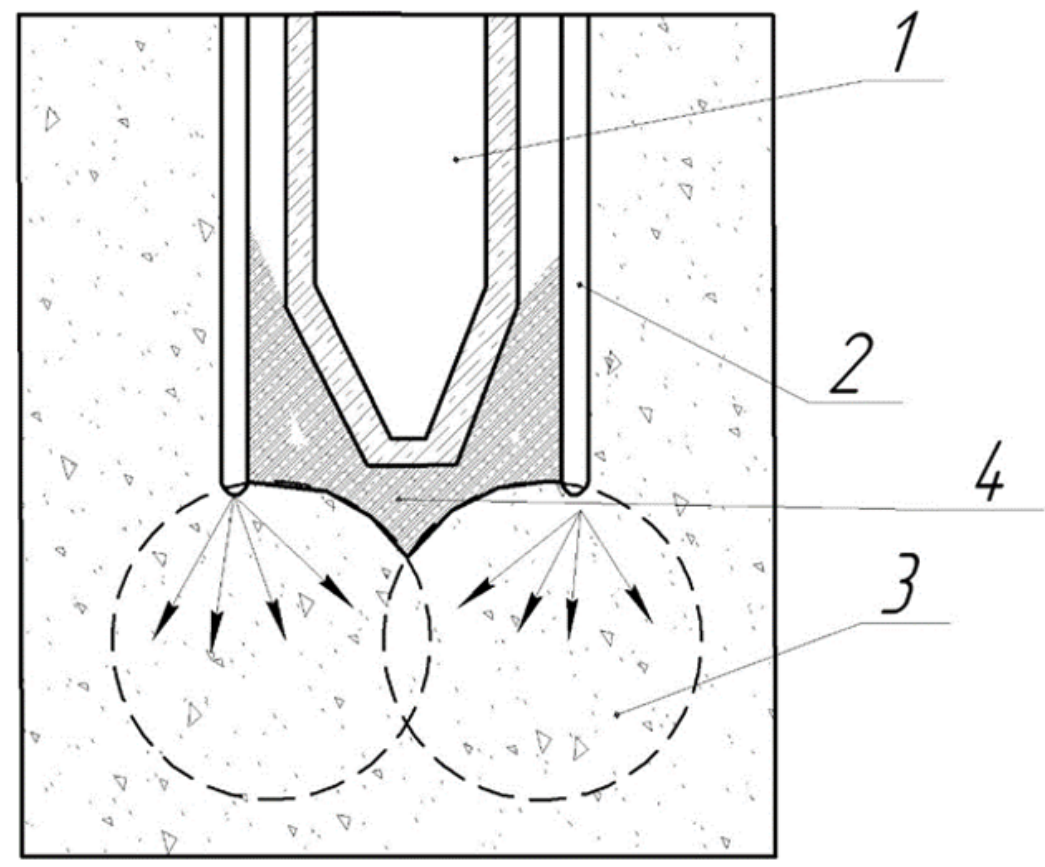

Fig.4. Installation of bank protection piles using the washing method (1-pile, 2-pressure hose, 3-area of soil erosion, 4-soil solution).

Each construction object has its own life cycle, which includes the stages of design, preparation for production and construction of the object, its subsequent operation. Design and construction processes are often performed in parallel. Therefore, a constant exchange of work results between design and construction organizations is required, which, as a rule, are geographically separated from each other and can use various computer equipment and software, sometimes incompatible with each other.

The construction of fundamentally new buildings and structures involves compliance with new requirements in terms of building codes and the content of processes supporting construction at all stages. The regulatory framework governing production processes in engineering fields is also changing. Thus, the use of information technology provides the specialist in architectural and construction profile the ability to quickly and efficiently [7].

\section{Way to prevent the collapse of steep river banks.}

The invention relates to hydraulic engineering and environmental construction and can be used to protect coastal zones from landslides and collapse of soil massifs. Such collapses are most likely with a large angle of the slope and its excessive height [8]. The collapse of the coast leads to shallowing of the reservoir, damage and even destruction of buildings located on or near the shore. The slope angle can be reduced by its preliminary, phased, partial destruction with the creation of additional terraces from the destroyed soil.

For example, a known method of forming terraces on a slope [9], including:

- soil sampling from a horizontal slit at the base of a steep slope;

- dumping from this soil a water guide shaft that isolates the bottom section adjacent to a steep slope from the main water stream;

- self-collapse of the soil peak formed after sampling a horizontal slit;

- leveling the self-collapsed soil canopy in an isolated section of the bottom so that the mark of the crest of the water guide shaft exceeds the mark of the terrace canvas.

The main disadvantage of this method is the great risk of land work associated with the selection of a horizontal gap at the base of a steep slope. With a high height of the coast and 
the moisture content of its base (washing from the side of the river), sudden collapse of large tracts of soil (landslides) is possible. The use for the formation of horizontal slots of hydraulic monitors [10], destroying the soil with a stream of river water from a safe distance, is complicated by the following contradiction:

- to increase the performance of the hydraulic monitor, it should be as close as possible to the destructible land mass;

- to increase the safety of the hydraulic monitor, it should be as far as possible from the destructible land mass (due to the inevitable collapse of the overlying soil layers).

This contradiction can be overcome with the help of the "transition to another dimension" method, when the hydraulic monitor starts its work from the top layer of the soil.

Therefore, it is necessary to deliver a hydraulic monitor and water to the very top of a steep coast. Such an arrangement will completely protect it from the impact of landslides and will allow it to come into direct contact with eroded soil and supplement the hydraulic effect with a mechanical one. That is, we can use a dredger with a mill for erosion of the soil massif [11]. This will increase the productivity of soil sampling by two orders of magnitude (linear and tangential instead of point impact). The dredger is delivered to the place of work by automotive equipment and placed by crane equipment in a previously dug up initial pool.

Two directional wells are drilled to deliver river water to the dredger and drain pulp from the shore to the river water level. To fill the initial pool, river water is supplied from below by a pressure pump. The dredger begins to work, eroding the upper tier of the steep bank and feeding the resulting pulp down to form a water guide shaft. Having finished removing soil from the first tier, the dredger makes an initial pool for itself in the next tier, and the finished tier is drained.

Another contradiction that interferes with the use of hydraulic washing is as follows:

- for ease of transportation, soil removed from the body of a steep coast should be liquid (pulp);

- for filling the water guide shaft, the soil must be dry (difficult to wash river flow).

This contradiction can be overcome by using "flexible shells and thin films", when the resulting pulp is fed not into the river stream, but into flexible containers from permeable geo-shells [12]. With this supply, water passes through the shell into the river, and the soil remains inside it.

The purpose of the invention: increasing the productivity of work on hydraulic washing of soils composing a steep bank, without compromising the safety of these works and the use of hydrotransport of removed soil without compromising its further use when dumping a water guide.

This goal is achieved in that the erosion of the soil and the formation of terraces begins with the upper layers of the soil for which a dredger is installed on the shore surface and two deviated wells are drilled from the shore surface to the river water edge to supply water to the soil erosion and remove the resulting pulp to fill the water guide shaft. At the same time, flexible containers of permeable geo-material are used to receive pulp.

The proposed method for preventing the collapse of a steep river bank consists of the following stages:

- drilling from the surface of the shore to the river water edge of two deviated wells for supplying water for erosion of the soil and removing the resulting pulp to fill the water guide shaft;

- creation of an initial basin by filling it with river water supplied from below through an inclined well and placing a dredger in the basin;

- work of a dredger to remove soil from the layer being developed and removing the resulting pulp down an inclined well down to fill, pulp filling containers from flexible 
geomaterial, forming a water guide shaft from the containers, filling the section between the shore and the formed water guide shaft with water to displace the river:

- repetition of the previous two stages on each successive tier until the shore is completely exhausted;

The proposed method allows:

- use not only hydraulic but also mechanical impact during soil erosion without compromising the safety of work;

- use the resulting pulp to form a water guide shaft.

The inventive method with its essential features can be repeatedly and in various ways, using various devices and materials, successfully implemented in practice to obtain the above result.

Example. The way to prevent the collapse of steep river banks is illustrated by the drawing in Fig. 1. The dredger (1) is delivered by road to the riverbank. To deliver river water (2) to the dredger, an inclined well (3) is drilled from the shore to the river water level. Moreover, in order for it to be involved in the technological process of erosion, the angle of its inclination must always coincide with the design slope angle.

Since the water level in the river is not constant, it will be necessary to use a float water intake device (4) equipped with a pump (5) to supply water to the required height and a flexible water pipe (6) to connect to the well exit.

The water-soil mixture (7) leaving the dredger (pulp) will need to be removed. To do this, next to the first water supply inclined well (3), we drill a second angle (8) at the same angle to divert the pulp from the dredger. To unload the pulp, we use a special float device (9) and a flexible pulp line (10). The pulp is unloaded into a flexible container from permeable geomaterial (11) For the convenience of setting up, such a container can be designed as a net with floats on the upper selection and weights on the lower, with the possibility of pulling together the lower and upper selection.

When pulp enters the container, water will flow into the river and the soil (12) will remain in the shell, filling it. When the shell is completely filled and connected in a line, a shore-guarding structure or a "retaining wall" is formed. The space between the shaft and the underwater part of the steep bank (13) can also be filled with pulp or bridge material (14) that separates the erosion zone (2) from the edge of the shore.

After completion of the development and drainage of the first tier, this jumper can be brought down from a safe distance into the aforementioned space using a hydraulic monitor mounted on a dredger (1). In the opposite jumper of the part of the drained layer, the upper sections of the boreholes (3) (8) will be exposed, which will make it possible to shorten them during the development of the next layer (Fig. 2). Part of the shore, for which the float device for unloading the pulp (9) will be moved from the contour of a flexible permeable shell to this space.

After the development and drainage of all tiers (Fig. 3), a system of terraces with a projected angle of the river slope is obtained. At the same time, all the soil developed by the dredger was used to construct a new boundary between the coast and moving river (2) waters: water - geotextile (11) and fill (liquidate) the former border of contact: water ground (13). Terraces can be used for planting shore-strengthening plants (14).

IPC E02 B3/12 Method for preventing the collapse of steep river banks. 


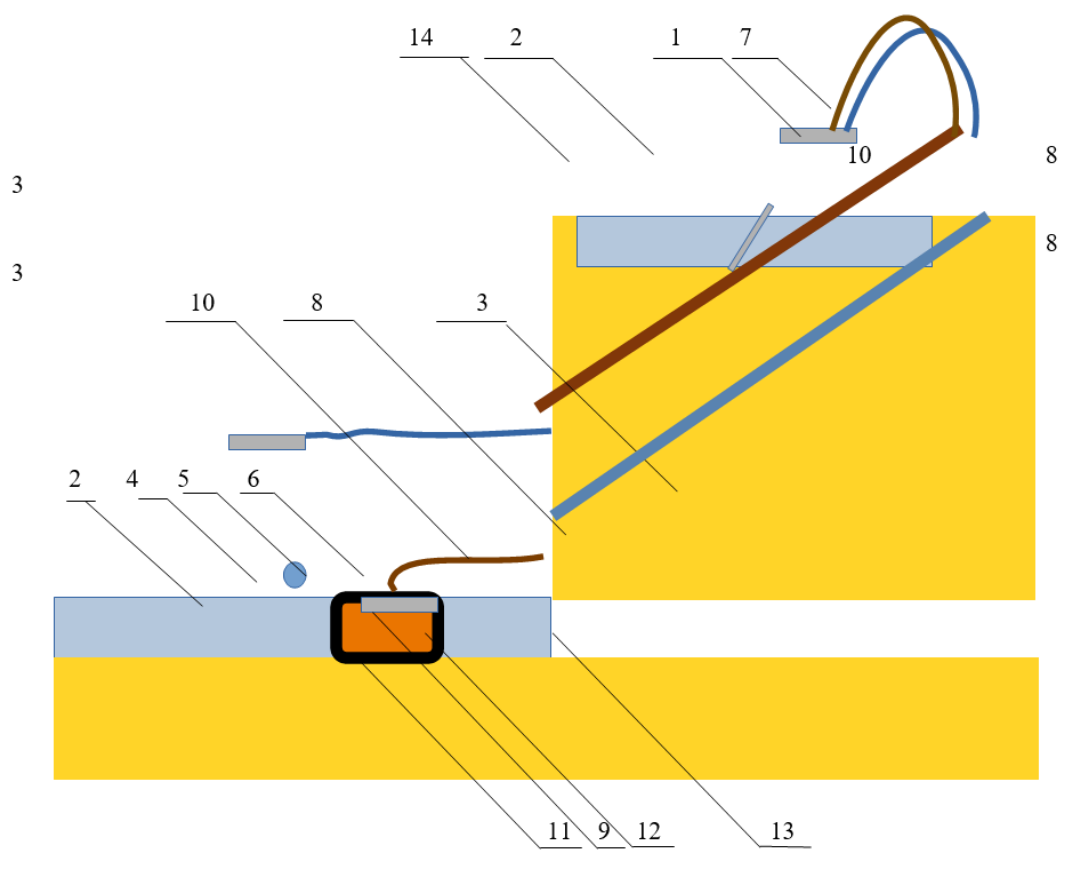

Fig. 5. A way to prevent the collapse of Steep River banks (first tier).

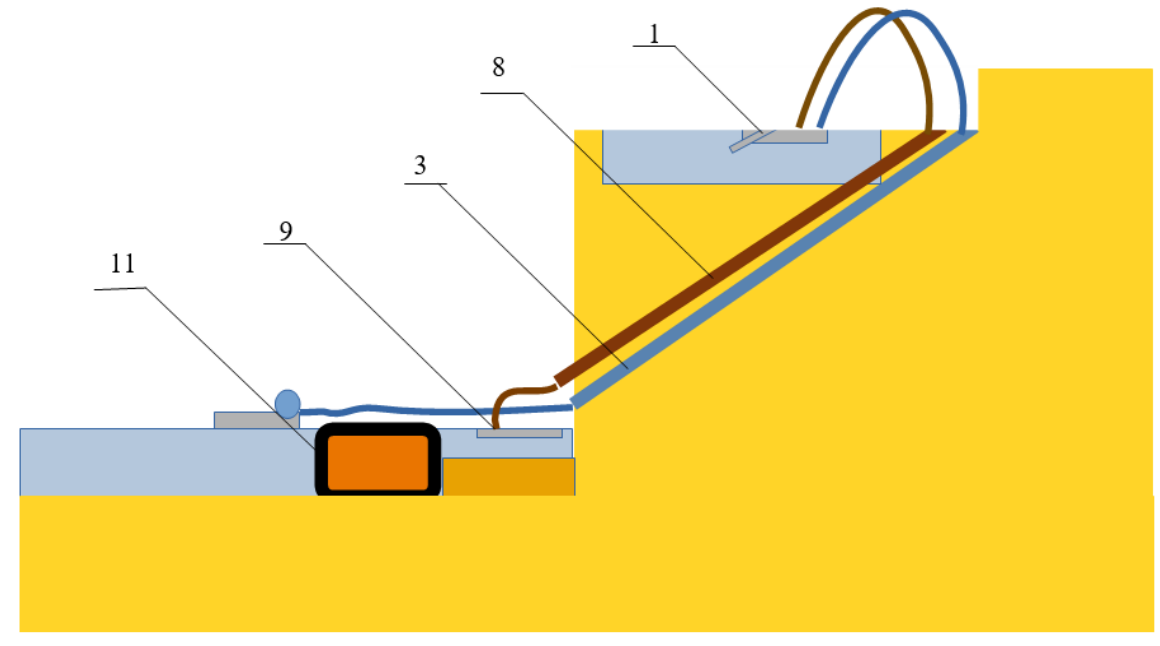

Fig. 6. A way to prevent the collapse of Steep River banks (second tier). 


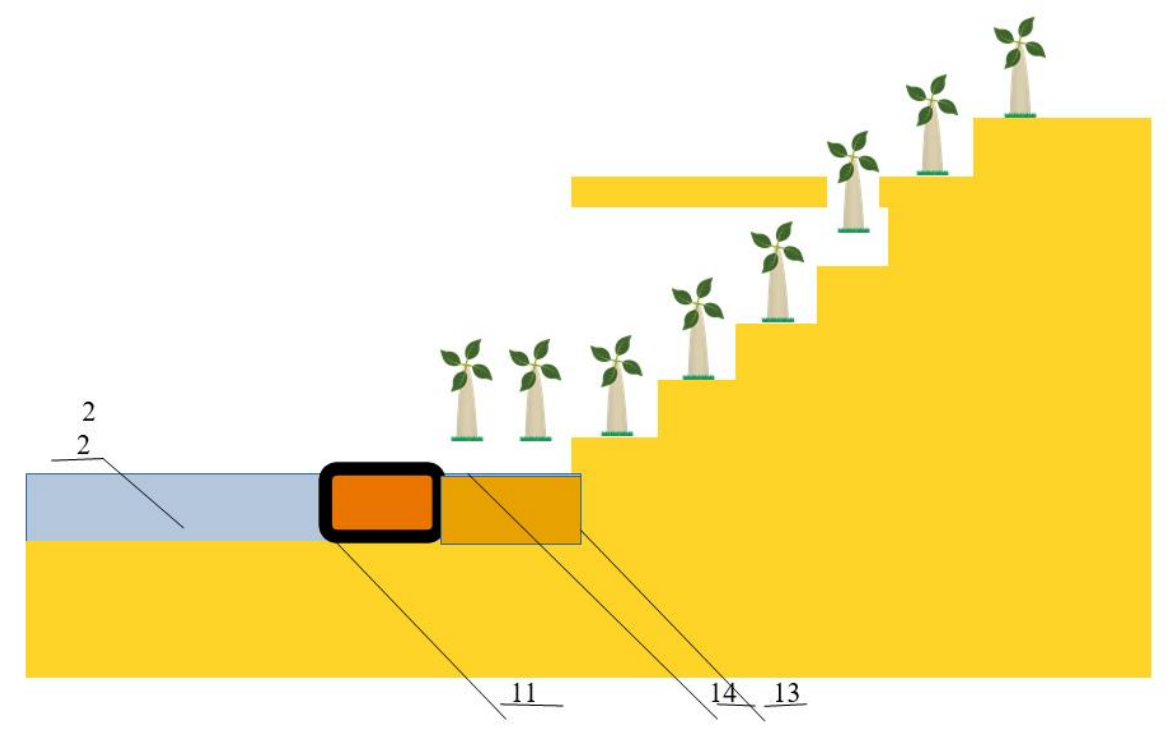

Fig. 7. Terrace system with projected river slope angle.

\section{Conclusion}

The positive effect of the monitoring method of coastal zones (with the subsequent shore protection of the territories of the most potentially destructible) will be manifested in comparison with the elimination of the consequences of such destruction (costly dredging).

The presented method for preventing the collapse of steep river banks fully interacts with the results of monitoring water bodies and, in the absence of violations in the construction and the correct selection of parameters of these structures, it is possible to recommend the use of research data in practice.

However, it was recommended that these hydraulic structures be tested on various sections of coastal zones with different rates of coastal destruction before the massive introduction of these technologies. Since, for example, during an earthquake, the degree of damage and collapse of structures is directly dependent on the potential of critical defects embedded in it [13]. That means monitoring not only water conditions, but also the established protective structures of coastal zones, is mandatory.

With present limited state economic contributions, private operators will be actors in shore protection management [14].

Including protection structures built in the past will become less effective as they deteriorate or their design elevations become exceeded. The increasing costs of protecting facilities, infrastructure, historic structures and other cultural resources will likely limit new projects to protection of only the most critical resources. [15]

\section{References}

1. M. Postacchini, A. Romano, Dyn. of the Coas. Zone (2019) DOI: 10.3390/jmse7120451

2. M. Ramkumar, R. A. James, D. Menier, K. Kumaraswamy, Coas. Zone Man (2019) https://doi.org/10.1016/B978-0-12-814350-6.00001-X 
3. M. L. A. Gomez, O. J. Adelegan, J. Ntajal, Dodou Trawally (2019) DOI: 10.1016/j.ijdrr.2019.101439

4. T.V. Zolina, P.N. Sadchikov, Mag. of Civil Eng. 84(8), 150-161 (2018) DOI: $\underline{10.18720 / \mathrm{MCE} .84 .15}$

5. T.-L. Gouw, (2016) DOI: 10.3208/jgssp.SEA-13

6. T.V. Zolina, I.A. Popova, Pot. Int. od. mol. 7, 68-73 (2018)

7. T.V. Zolina, S.V. Rasskazova, Per. developed page comp. 12, 433-437 (2018)

8. Electronic resource: URL:https://studfile.net/preview/8153987/ (2019)

9. V.M. Ivonin, Sh.T. Mukaev, A.S. USSR N 1752208 IPC A01B 13/16 patent

10. G.P. Stepanov, F.I. Koziin, A.S. USSR N 1604991 IPC E21C 45/00 patent

11. D.V. Roshchupkin, F.T. Pimenov, Yu.M. Kuznetsov, A.A. Tsernant, A.S. USSR N 848542 IPC E02F 3/90 patent

12. Electronic resource: https://remstd.ru/archives/sovremennyie-tehnologiiberegoukrepleniya (2015)

13. T.V. Zolina, P.N. Sadchikov, Adv. Mat., Str. \& Mech. Eng., 115-118 (2016) DOI: 10.1201/b19693-25

14. E. Pranzini, Oce. \& Coast. Man. 15615, 43-57 (2018) https://doi.org/10.1016/j.ocecoaman.2017.03.029

15. K.F. Nordstrom, N. L. Jackson, C. T. Roman, Env. Sc. \& Pol. 66, 217-226 (2016) https://doi.org/10.1016/j.envsci.2016.07.012 